\title{
Analysis of Cost of Production for Potato Pastel (Case Study: Home Industry, Palembang)
}

\section{Analisis Harga Pokok Produksi Pastel Kentang (Studi Kasus : Home Industry, Palembang)}

\author{
Ervina Novita ${ }^{1}$ \\ 1 Teknik Industri \\ Universitas Katolik Musi Charitas Palembang, Jl. Bangau No. 60, 12345 \\ email : ervinanov19@gmail.com \\ doi: https://doi.org/10.31315/opsi.v14i1.4787
}

Received: 22 nd May 2021; Revised: 22 $2^{\text {nd }}$ June 2021; Accepted: $22^{\text {nd }}$ June 2021;

Available online: $24^{\text {th }}$ June 2021; Published regularly: June 2021

\begin{abstract}
The home industry is a business that is managed on a small scale. The home industry is a business that is flexible and can be run by anyone who has the ability to manage their own business. One of the home industries located in the city of Palembang is the home industry. This home industry only employs 4-7 employees in its business to produce 250 pastels. In terms of financial management, this home industry does not have special bookkeeping to calculate the business it is running, so that this home industry does not clearly know the costs and benefits of this home industry. Engineering economics is a science that is studied in studying industrial engineering. Engineering economics can be used to analyze the costs and benefits of solving a problem. Technical economics can be used to evaluate finances during the home industry business process. Profits and costs are closely related to the cost of goods manufactured and the break-even point in production.
\end{abstract}

Keywords: Cost of goods sold; Break-even Point; Engineering Economics; Home industry

\section{ABSTRAK}

Home industry merupakan sebuah usaha yang dikelola dalam skala kecil. Home industry merupakan suatu bisnis yang fleksibel dan dapat di jalankan oleh siapa saja yang punya kemampuan dalam mengelola usahanya sendiri. Salah satu home industri yang terletak di kota Palembang, adalah home industry. Home industry ini hanya memperkerjakan 4-7 orang karyawan dalam bisnisnya untuk memproduksi 250 buah pastel. Dari segi pengelola keuangan, home industry ini tidak mempunyai pembukuan khusus untuk melakukan perhitungan atas usaha yang dijalankan, sehingga home industry ini tidak mengetahui dengan jelas biaya dan keuntungan yang didapatkan dari home industry ini. Ekonomi teknik merupakan ilmu yang dipelajari dalam menempuh pendidikan di jurusan teknik industri. Ilmu ekonomi teknik dapat digunakan untuk menganalisis biaya dan keuntungan untuk memecahkan suatu masalah. Ekonomi teknik dapat dijadikan untuk mengevaluasi keuangan selama proses bisnis home industry berjalan. Keuntungan dan biaya berkaitan erat dengan harga pokok produksi dan titik impas dalam produksi.

Kata Kunci: Harga Pokok Produksi; Titik Impas; Ekonomi Teknik; Home industry

\section{PENDAHULUAN}

Dunia bisnis dan industri berkembang begitu pesat, sehingga butuh sebuah ilmu yang mampu menyesuaikan dengan perkembangan bisnis, dan industri, serta masalah yang dihadapi untuk saat ini. Para pemilik bisnis merupakan mereka yang memegang keputusan terpenting dalam usahanya, sehingga mereka perlu mengambil keputusan yang tepat untuk menjamin kelangsungan bisnis yang mereka jalani. Dalam ilmu ekonomi teknik, seorang pengambil keputusan dihadapkan kepada alternatif rancangan (design) atau pemecahan 
suatu masalah yang lain yang semakin kompleks dimana satu diantaranya harus dipilih (Giatman, 2006). Ilmu ekonomi teknik adalah ilmu yang digunakan dalam menentukan faktor dan kriteria ekonomi yang digunakan untuk menyelesaikan masalah dalam bidang teknik. Ilmu ekonomi teknik dapat digunakan untuk menganalisis kelayakan suatu usaha. Kelayakan suatu usaha dapat dilihat dari laba produksi yang di dapatkan oleh perusahaan tersebut.

Untuk menentukan suatu usaha layak atau tidak, maka lakukan analisis harga pokok produksi dengan tujuan untuk mengetahui berapa jumlah biaya yang dikeluarkan untuk melakukan proses produksi produk tersebut. Analisis harga pokok produksi dapat membantu pengusaha dalam menentukan harga jual produk yang tepat dan sesuai dengan harapan pengusaha tersebut.

Sebagian besar masyarakat Indonesia menyukai untuk mengonsumsi makanan sejenis snack berupa gorengan. Banyak pelaku usaha dalam skala home industry yang memulai bisnis untuk memproduksi gorengan. Saat ini home industry merupakan salah satu prospek usaha yang menjanjikan. Home industry dapat dijalani oleh siapa saja yang mempunyai kemampuan untuk memproduksi suatu produk. Home industry merupakan usaha atau perusahaan dalam skala kecil yang bergerak dalam bidang industri tertentu. Walaupun jenis usaha yang tergolong home industry merupakan usaha kecil, namun home industry mampu membantu perekonomian para pekerjanya. Industri rumah tangga yaitu industri yang mempunyai tenaga kerja yang terbatas hasil produksi (Rita, Lusi Maretti dan Sutrisna, 2016).

Home industry biasanya memiliki karyawan yang sangat sedikit untuk menghasilkan produk yang mereka buat. Dalam home industry yang dikelola oleh Ibu Foni, Ibu Foni hanya mempekerjakan 4-7 orang dalam proses pembuatan pastel sehingga tidak ada bagian khusus yang melakukan pembukuan atas usaha yang dijalankan oleh Ibu Foni. Seharusnya, dalam menetapkan harga jual suatu produk, diperlukan perhitungan harga pokok produksi untuk mengetahui berapa harga jual yang sesuai dan jumlah keuntungan yang diperoleh oleh Home industry tersebut. Pembukuan sangat penting dilakukan oleh pemilik bisnis demi kepentingan untuk mengambil keputusan yang tepat. Pemilik bisnis merupakan pemegang keputusan yang utama dalam membangun sebuah bisnis. Kemajuan dari bisnis dapat dilihat dari pembukuan yang dibuat dan dari keputusan pemilik home industry itu sendiri.

. Saat pandemi COVID-19 melanda, banyak perusahaan yang terencana bangkrut sehingga harus menggurangi jumlah pegawai yang bekerja. Salah satu lapangan pekerjaan yang mampu menyerap jumlah pekerja, adalah lapangan pekerjaan yang diciptakan oleh home industry, khususnya home industry yang memproduksi makanan. Home industry yang memproduksi makanan, cenderung digemari oleh masyarakat belakangan ini dan hal ini dapat dibuktikan dengan menjamurnya bisnis kuliner yang dapat kita lihat di marketplace seperti instagram, facebook dll.

UMKM yang di kelola oleh Ibu Foni, merupakan salah satu home industry yang mengaku penghasilannya sedikit meningkat sejak pandemi COVID-19. Industry ini mengalami peningkatan produksi sebanyak ratarata 80 buah/hari karena bisnis kuliner Online yang mereka jalani. Ibu Foni mengelola sebuah home industry yang terletak di kota Palembang. Home industry ini adalah home industry yang menjual snack berupa makanan, yaitu pastel. Saat ini permintaan akan produk pastel ini sangat digemari oleh masyarakat, sehingga prospek bisnis home industry yang memproduksi pastel cukup menjanjikan. Pastel kentang merupakan salah satu makanan yang sering dicari oleh masyarakat di kota Palembang. Apabila di bandingkan dengan pempek, salah satu makanan khas kota Palembang, pastel memiliki harga yang cukup murah. Rata-rata restoran yang menjual 1 buah pempek di kota Palembang, menjual pempek dengan kisaran harga Rp. 3.500-5.000. Sedangkan untuk 1 buah pastel, dijual dengan harga rata-rata Rp. 1.000-Rp. 3.500.

Saat ini, kebanyakan dari pelaku bisnis home industry tidak melakukan perhitungan mengenai harga pokok produksi dan menjual produknya berdasarkan harga rata-rata pesaing dari produknya. Untuk membantu pelaku bisnis home industry yang menjual makanan berupa snack pastel, penulis mencoba meneliti harga pokok produksi sebuah produk berbasis home industry yang ada di Kota Palembang. 


\section{METODE}

Harga pokok produksi akan terkait pada harga jual dan keuntungan penjualan yang didapatkan. Harga pokok produksi selalu berhubungan dengan biaya bahan baku, alat produksi dan sebagainya. Dalam memperhitungkan unsur-unsur biaya dalam harga pokok produksi, terdapat dua pendekatan yaitu full costing dan variable costing (Pelealu, Manoppo, \& Mangindaan, 2018). Metode full costing menghitung semua unsur biaya produksi, mulai dari biaya bahan baku hingga biaya overhead pabrik dan variable costing hanya memasukan biaya variabel produk untuk mendapatkan harga pokok produksi. Kelebihan metode full costing adalah menghitung harga pokok produksi sampai ke biaya overhead (biaya yang tidak berakitan langsung dengan distribusi produk) dan variable costing merupakan metode yang sangat cocok untuk digunakan untuk menghitung keuntungan dalam jangka waktu pendek.

Penulis melakukan penelitian di kota Palembang, Sumatera Selatan dan penelitian ini dilakukan pada 1 April - 10 April 2021 bertempat di Jalan Srijaya Negara, Palembang, Sumatera Selatan. Berikut adalah Alat dan Bahan yang digunakan pada penelitian ini :

a. Baskom dan adonan terigu (Gambar 1)

b. Mesin penipis adonan (Gambar 2)

c. Mangkuk kecil dan pisau (Gambar 3)

d. Bahan Baku Isi berupa kentang dan wortel (Gambar 4)

e. Pisau pemotong kentang (Gambar 5)

f. Talenan (Gambar 6)

g. Kuali besar (gambar 7)

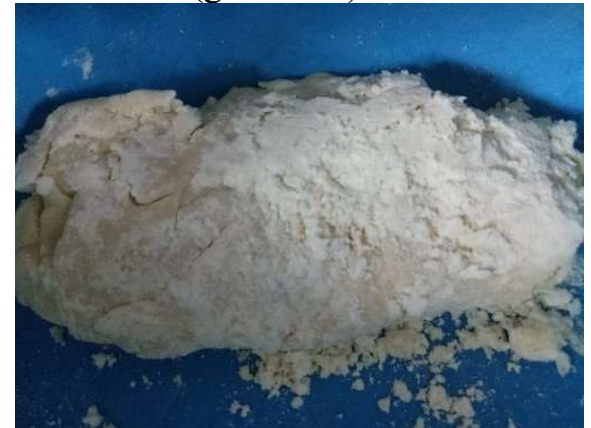

Gambar 1. Baskom dan Adonan Terigu

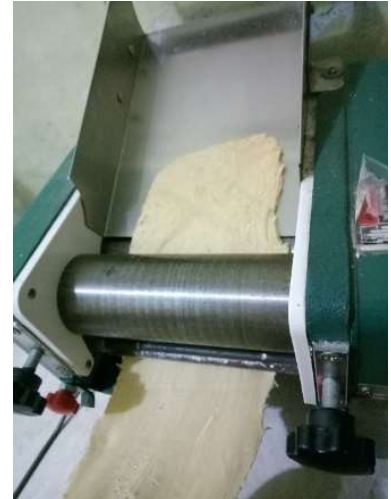

Gambar 2. Mesin Penipis Adonan

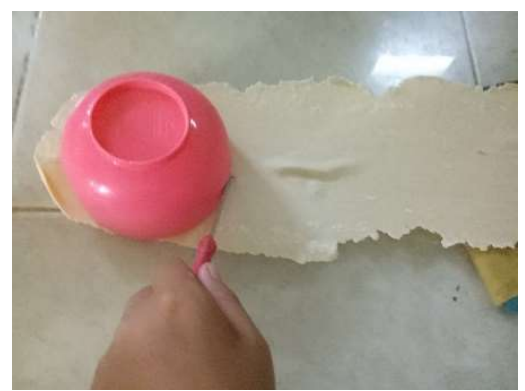

Gambar 3. Mangkuk Kecil dan Pisau

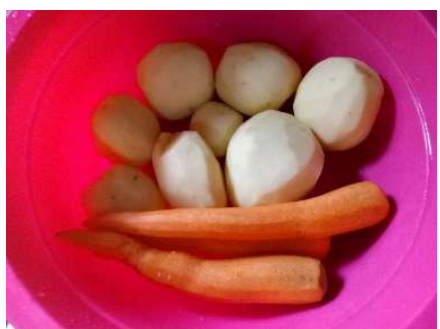

Gambar 4. Bahan Baku Isi

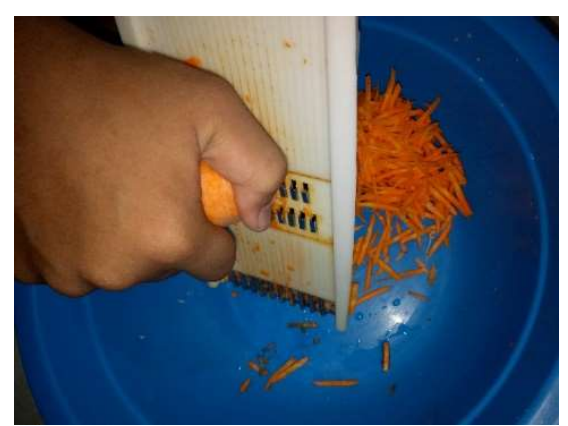

Gambar 5. Pisau pemotong kentang

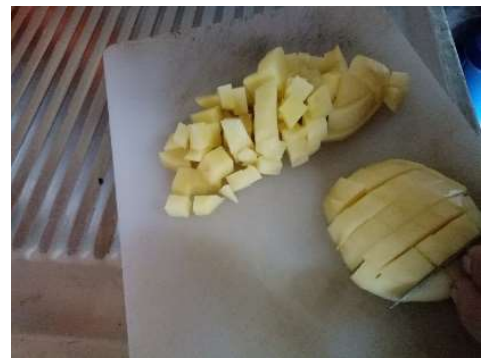

Gambar 6. Talenan 


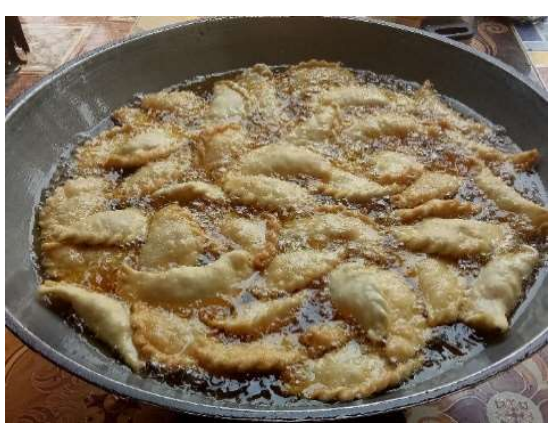

Gambar 7. Kuali Besar

\subsection{Metode Pengumpulan Data}

Penulis melakukan pengumpulan data primer dan data sekunder. Data primer didapatkan melalui pengamatan sendiri home industry pastel ini dan wawancara dengan pemilik home industry ini, dan data sekunder di dapatkan dengan melihat publikasi ilmiah yang berkenaan dengan home industry. Penelitian dilakukan berdasarkan asumsi dan pendekatan sebagai dasar dalam melakukan perhitungan dan analisis. Asumsi dan dengan pendekatan yang terdiri dari umur ekonomis proyek ini adalah 12 tahun, harga akhir peralatan adalah $10 \%$ dari harga awal, tingkat suku bunga $9 \%$ efektif pertahun, biaya manajemen Rp. 500.000/bulan, kapasitas pengupasan manual $2 \mathrm{~kg} / \mathrm{jam}$, biaya perawatan peralatan adalah $2 \%$ dari biaya investasi, jam kerja 8 jam/hari, kapasitas produksi/hari 250 buah, minyak goreng Rp. $12.000 / \mathrm{kg}$, terigu Rp. $8.000 / \mathrm{kg}$, kentang Rp. $10.000 / \mathrm{kg}$, wortel $\mathrm{Rp}$. $9.000 / \mathrm{kg}$, bahan bakar gas Rp. $3.600 / \mathrm{kg}$, kemasan plastik Rp. $10.000 / \mathrm{kg}$, harga satuan produk Rp. 1.500 dan biaya listrik Rp. $300.000 /$ bulan. Biaya investasi adalah biaya tetap yang besarnya tidak dipengaruhi oleh jumlah produk yang dihasilkan. (Noodle, Tirta, Wening, Kartika, \& Mayasti, 2014).

\subsection{Metode Analisis}

\subsubsection{Analisis Penyusutan}

Besarnya biaya penyusutan peralatan produksi diperhitungkan dengan menggunakan metode garis lurus yang dirumuskan sebagai berikut (Thoriq, Sampurno, \& Nurjanah, 2017) :

$$
\mathrm{D}=\mathrm{P}-\mathrm{SN} \text { (1) }
$$

Keterangan :

$\mathrm{D}=$ biaya penyusutan pertahun (Rp/tahun)

$\mathrm{P} \quad=$ harga awal peralatan $(\mathrm{Rp})$
$\mathrm{S}=$ harga akhir peralatan (Rp)

$\mathrm{N}=$ perkiraan umur ekonomis (tahun)

\section{Analisis Biaya Produksi}

Biaya produksi adalah biaya yang dijumlahkan dari biaya tetap dan biaya variabel. Besarnya biaya produksi di hitung menggunakan persamaan sebagai berikut:

$$
\mathrm{BP}=\mathrm{BT}+\mathrm{BV}(2)
$$

$$
\begin{aligned}
& \text { Keterangan : } \\
& \text { BP = Biaya Produksi (Rp/tahun) } \\
& \text { BT = Biaya Tetap }(\mathrm{Rp} / \text { tahun }) \\
& \text { BV }=\text { Biaya Variabel (Rp/tahun) }
\end{aligned}
$$

Biaya Variabel Biaya variabel adalah biaya yang jumlah totalnya berubah sebanding dengan perubahan volume kegiatan (Setiyani, 2015).

Biaya tetap adalah biaya yang secara total tetap dalam rentang relevan (relevant range) tetapi per-unit berubah. Biaya campuran adalah biaya yang mengandung unsur biaya tetap dan biaya variabel (Maghfirah \& Syam BZ, 2016).

\subsubsection{Analisis Harga Pokok Produksi}

Harga pokok produksi adalah cara memperhitungkan unsur-unsur biaya ke dalam kos produksi. (Mulyadi, 2013). Menurut arti lain, harga pokok produksi adalah pengorbanan sumber ekonomi yang diukur dengan satuan uang untuk memperoleh penghasilan (Anita, 2014). Harga pokok produksi merupakan total biaya yang dikeluarkan untuk memproduksi suatu produk. Harga pokok produksi (HPP) dapat dihitung dengan menggunakan persamaan sebagai berikut :

$$
\begin{aligned}
& \mathrm{HPP}=\frac{\mathrm{BP}}{\mathrm{PT}}(3) \\
& \text { Keterangan }: \\
& \mathrm{HPP}=\text { Harga Pokok Produksi (Rp/unit) } \\
& \mathrm{BP}=\text { Biaya produksi (Rp/tahun) } \\
& \mathrm{PT}=\text { Produksi Total (unit/tahun) }
\end{aligned}
$$

\subsubsection{Titik Impas Produksi}

Harga pokok produksi merupakan sesuatu yang telah dikorbankan selama periode tertentu guna mencapai suatu penghasilan (Maruta, 2018). Penghasilan akan berhubungan dengan titik impas dalam suatu usaha. Analisa titik impas merupakan cara untuk mengetahui pada titik apa home industry ini mendapat keuntungan atau sebaliknya. Titik impas produksi dapat dihitung dengan rumus:

$$
\mathrm{BEP}=\frac{\mathrm{BT}}{\mathrm{HJ}-\mathrm{BVR}}(4)
$$


Keterangan :

$\mathrm{BEP}=$ Titik Impas Produksi (unit/tahun)

BT $=$ Biaya Tetap $(\mathrm{Rp} /$ tahun $)$

$\mathrm{HJ}=$ Harga jual $(\mathrm{Rp} / \mathrm{unit})$

$\mathrm{BVR}=$ Biaya Variabel Rata-rata (Rp/unit)

\section{HASIL DAN PEMBAHASAN}

Usaha adalah cara manusia untuk memenuhi kebutuhan hidupnya. Bidang usaha tidak terlepas dari kegiatan investasi. Investasi merupakan hal penting untuk diperhatikan dalam tujuan untuk mendapatkan keuntungan dalam jangka waktu yang panjang. Investasi adalah suatu kegiatan untuk menanamkan uang atau modal dalam suatu proyek dengan tujuan untuk mendapatkan keuntungan. Pada usaha produksi pastel secara manual, dibutuhkan investasi peralatan produksi serta variabel dan asumsi usaha dapat dilihat pada Tabel 1 dan tabel 2.

Untuk memproduksi pastel ini, tentunya di pengaruhi oleh biaya tetap dan biaya variabel. Biaya yang termasuk dalam biaya tetap ini adalah biaya yang setiap bulannya pasti di keluarkan. Biaya itu antara lain adalah biaya penyusutan peralatan, biaya perawatan peralatan, biaya manajemen, bunga modal dan biaya listrik. Secara lengkap, biaya ini disajikan dalam tabel 3.

Berdasarkan tabel 3, dapat dilihat total biaya tetap yang harus di keluarkan per bulan adalah sebesar Rp. 695.100. Selain biaya tetap, terdapat biaya variabel yang besarnya ditentukan oleh banyaknya pastel yang di produksi. Biaya yang termasuk dalam biaya variabel ini adalah biaya bahan baku. Biaya yang termasuk dalam biaya ini adalah biaya untuk membeli minyak goreng, terigu, kentang, wortel, bahan bakar gas, plastik untuk kemasan. Secara rinci, biaya tersebut dapat dilihat pada tabel 4.

Dari tabel 4, dapat diketahui biaya variabel untuk produksi pastel $/ \mathrm{kg}$ adalah sebesar $\mathrm{Rp}$. 52.600. Biaya variabel ini akan digunakan untuk menghitung biaya produksi pastel dengan rumus $\mathrm{BP}=\mathrm{BT}+\mathrm{BV}$. Berdasarkan perhitungan, diketahui bahwa:

$$
\begin{aligned}
& \mathrm{BT}=695.100 / \mathrm{bulan} \\
& \mathrm{BV}=52.600 / \mathrm{kg} .
\end{aligned}
$$

Untuk membuat 250 buah pastel, dibutuhkan $5 \mathrm{~kg}$ bahan baku. Maka, BV/bulan adalah

$$
\begin{aligned}
& \mathrm{BV}=(\mathrm{Rp} .52 .600 * 5) \times 30 \text { hari } \\
& \mathrm{BV}=\mathrm{Rp} .7 .890 .000 / \text { bulan } \\
& \mathrm{BP}=\mathrm{Rp}(695.100+7.890 .000) \\
& \mathrm{BP}=\operatorname{Rp} .8 .585 .100
\end{aligned}
$$

Sehingga, biaya produksi pastel/bulan adalah sebesar Rp. 8.585.100.

Untuk menghitung harga pokok produksi pastel, diperlukan untuk mencari Biaya Produksi (BP) lalu dibagi dengan produksi total (PT). Berdasarkan perhitungan diketahui bahwa biaya produksi pastel/bulan adalah sebesar Rp. 8.585.100. Pastel yang di produksi/hari adalah sebanyak 250 buah dan selama sebulan ada 7.500 pastel yang di produksi. Sehingga :

$$
\begin{aligned}
& \mathrm{BP}=\text { Rp. } 8.585 .100 / \text { bulan } \\
& \begin{aligned}
\mathrm{PT} & =\mathrm{Rp} .7 .500 / \text { bulan } \\
\mathrm{HPP} & =\mathrm{BP} / \mathrm{PT} \\
& =\mathrm{Rp} .(8.585 .100 / 7.500) \\
& =\text { Rp. } 1.145 / \text { buah }
\end{aligned}
\end{aligned}
$$

Sehingga, untuk memproduksi 1 buah pastel, membutuhkan biaya sebesar Rp. 1.145/buah.

BEP adalah satu cara untuk mengetahui apakah usaha pastel ini mengalami keuntungan atau kerugian. BEP bisa didapatkan dengan rumus pada persamaan 4. Dari data dan perhitungan yang ada, dapat di ketahui :

$$
\begin{aligned}
& \mathrm{BT}=\mathrm{Rp} .695 .100 / \text { bulan } \\
& \mathrm{HJ}=\mathrm{Rp} .1 .500 / \text { buah } \\
& \mathrm{BVR}=\mathrm{Rp} .1 .052 / \text { buah } \\
& B E P=\frac{R p .695 .100}{(R p .1500)-(\text { Rp. 1.052) }}
\end{aligned}
$$

$\mathrm{BEP}=1.552 \mathrm{Buah} /$ bulan

Jadi, agar usaha ini tidak mengalami kerugian, maka dibutuhkan produksi sebesar 1.552 buah pastel/bulan. Sedangkan, home industry ini memproduksi sebanyak 250 buah pastel yang rata-rata setiap harinya selalu habis. Sehingga bisa dipastikan bahwa home industry ini jelas mengalami keuntungan.

Pendapatan penjualan pastel ini didapatkan dari banyaknya pastel yang terjual. Di asumsikan pada tahun pertama home industry ini hanya mampu menjual sebanyak 100 buah/hari. Maka per bulan nya ada 3.000 pastel yang terjual sehingga pendapatan di tahun pertamanya adalah Rp. 54.000.000. Sedangkan di tahun kedua diasumsikan pastel yang terjual 
Tabel 1. Biaya Investasi Usaha Produksi Pastel

\begin{tabular}{cccccc}
\hline NO & Nama Perabotan & Jumlah & Satuan & Harga Satuan (Rp) & Harga Total (Rp) \\
\hline $\mathbf{1}$ & Pisau & 3 & Buah & 30.000 & 90.000 \\
\hline $\mathbf{2}$ & Talenan Plastik & 3 & Buah & 50.000 & 150.000 \\
\hline $\mathbf{3}$ & Baskom Besar & 6 & Buah & 50.000 & 300.000 \\
\hline $\mathbf{4}$ & Mesin Penipis Adonan & 1 & Unit & 2.500 .000 & 2.500 .000 \\
\hline $\mathbf{5}$ & Panci Presto & 2 & Buah & 400.000 & 800.000 \\
\hline $\mathbf{6}$ & Kuali Besar & 1 & Buah & 600.000 & 600.000 \\
\hline $\mathbf{7}$ & Spatula & 1 & Buah & 60.000 & 60.000 \\
\hline $\mathbf{8}$ & Alas Pemotong Adonan & 1 & Buah & 400.000 & 400.000 \\
\hline $\mathbf{9}$ & Mangkuk Kecil & 4 & Buah & 50.000 & 50.000 \\
\hline $\mathbf{1 0}$ & Peniris & 1 & Buah & 70.000 & 70.000 \\
\hline \multicolumn{7}{r}{} & & & & $\mathbf{5 . 0 8 0 . 0 0 0}$ \\
\hline
\end{tabular}

Tabel 2. Variabel Data Dan Asumsi Usaha Produksi Pastel

\begin{tabular}{|c|c|c|c|c|}
\hline NO & Uraian & Nilai & Satuan & Keterangan \\
\hline 1 & Umur Proyek & 12 & tahun & $\begin{array}{c}\text { Berdasarkan awal mula } \\
\text { UKM Beroperasi }\end{array}$ \\
\hline 2 & Suku Bunga Bank & 9 & $\%$ efektif & Kredit Usaha Rakyat \\
\hline 3 & nilai rongsok peralatan & 10 & $\%$ dari harga investasi & Asumsi \\
\hline 4 & Manajemen & 500.000 & $\mathrm{Rp} /$ Bulan & Asumsi \\
\hline 5 & $\begin{array}{c}\text { Kapasitas Pengupasan } \\
\text { Manual }\end{array}$ & $2 \mathrm{~kg} / \mathrm{jam}$ & $\begin{array}{l}\text { Hasil Pengukuran Jam } \\
\text { Kerja x Kapasitas } \\
\text { Pengupasan }\end{array}$ & Asumsi \\
\hline 6 & Biaya Perawatan Peralatan & 2 & $\%$ dari biaya investasi & Asumsi \\
\hline 7 & Jam Kerja & 8 & Jam/hari & Kondisi Nyata \\
\hline 8 & Kapasitas Produksi/hari & 250 & Rata-rata jumlah produksi & kondisi Nyata \\
\hline 9 & Minyak Goreng & 12000 & $/ \mathrm{kg}$ & Harga pasaran \\
\hline 10 & Terigu & 8000 & $/ \mathrm{kg}$ & Harga pasaran \\
\hline
\end{tabular}

Tabel 3. Biaya Tetap Usaha Pastel

\begin{tabular}{cccc}
\hline No & Biaya & $\begin{array}{c}\text { Biaya Tetap/Tahun } \\
(\mathbf{R p} / \text { Tahun })\end{array}$ & Biaya Tetap (Rp/ Bulan) \\
\hline $\mathbf{1}$ & Biaya Penyusutan Peralatan & 508.000 & 42.333 \\
\hline $\mathbf{2}$ & Biaya Perawatan Peralatan & 101.600 & 8.467 \\
\hline $\mathbf{3}$ & Biaya manajemen & 6000000 & 500.000 \\
\hline $\mathbf{4}$ & Bunga Modal & 457.200 & 114.300 \\
\hline $\mathbf{5}$ & Biaya Listrik & 3600000 & 30000 \\
\hline & Total Biaya & 10.666 .800 & 695.100
\end{tabular}

adalah sebanyak $150 \mathrm{buah} / \mathrm{hari}$ atau sekitar 4.500 pastel yang terjual dengan total pendapatan di tahun kedua adalah sebesar Rp. 81.000.000. di tahun ketiga hingga tahun ke 12, diasumsikan jumlah pastel yang terjual per hari adalah 250 buah dengan total pendapatan pertahunnya adalah Rp. 135.000.000. Sedangkan, untuk pengeluaran tetap per tahunnya dari perhitungan di dapatkan sebesar Rp. 103.021.200. untuk biaya tetap yang di keluarkan di tahun pertama, diasumsikan $40 \%$ dari biaya tetap saat ini, dan biaya tetap di tahun kedua diasumsikan $60 \%$ dari biaya tetap saat ini. Secara rinci, pemasukan dan pengeluaran untuk proyek ini selama 12 tahun dapat di lihat pada tabel 5.

Berdasarkan tabel 5, dapat dilihat jika pada tahun ke-0 belum didapatkan keuntungan karena usaha ini harus berinvestasi untuk membeli peralatan yang di butuhkan sebesar Rp. 5.080.000. Sedangkan pada tahun pertama penjualan, di dapatkan keuntungan sebesar Rp. 
Tabel 4. Biaya Variabel Produksi Pastel

\begin{tabular}{ccc}
\hline No & Biaya & Biaya Variabel (Rp/kg) \\
\hline $\mathbf{1}$ & Minyak Goreng & 12000 \\
\hline $\mathbf{2}$ & Terigu & 8000 \\
\hline $\mathbf{3}$ & Kentang & 10000 \\
\hline $\mathbf{4}$ & Wortel & 9000 \\
\hline $\mathbf{5}$ & Bahan Bakar Gas & 3600 \\
\hline $\mathbf{6}$ & Kemasan Plastik 2kg & 10000 \\
\hline & Total & 52600 \\
\hline
\end{tabular}

Tabel 5. Keuntungan Home industry Pastel

\begin{tabular}{cccc}
\hline Tahun & Pemasukan (Rp/Tahun) & Pengeluaran (Rp/Tahun) & Keuntungan (Rp/Tahun) \\
\hline $\mathbf{0}$ & - & $5.080 .000,00$ & $(5.080 .000,00)$ \\
\hline $\mathbf{1}$ & $54.000 .000,00$ & $41.208 .400,00$ & $12.791 .600,00$ \\
\hline $\mathbf{2}$ & $81.000 .000,00$ & $61.812 .720,00$ & $19.187 .280,00$ \\
\hline $\mathbf{3}$ & $135.000 .000,00$ & $103.201 .200,00$ & $31.798 .800,00$ \\
\hline $\mathbf{4}$ & $135.000 .000,00$ & $103.201 .200,00$ & $31.798 .800,00$ \\
\hline $\mathbf{5}$ & $135.000 .000,00$ & $103.201 .200,00$ & $31.798 .800,00$ \\
\hline $\mathbf{6}$ & $135.000 .000,00$ & $103.201 .200,00$ & $31.798 .800,00$ \\
\hline $\mathbf{7}$ & $135.000 .000,00$ & $103.201 .200,00$ & $31.798 .800,00$ \\
\hline $\mathbf{8}$ & $135.000 .000,00$ & $103.201 .200,00$ & $31.798 .800,00$ \\
\hline $\mathbf{9}$ & $135.000 .000,00$ & $103.201 .200,00$ & $31.798 .800,00$ \\
\hline $\mathbf{1 0}$ & $135.000 .000,00$ & $103.201 .200,00$ & $31.798 .800,00$ \\
\hline $\mathbf{1 1}$ & $135.000 .000,00$ & $103.201 .200,00$ & $31.798 .800,00$ \\
\hline $\mathbf{1 2}$ & $135.000 .000,00$ & $103.201 .200,00$ & $31.798 .800,00$ \\
\hline
\end{tabular}

12.791.600 karena usaha ini masih baru dan belum banyak pelanggan yang membeli. Pada tahun ke dua, keuntungan mulai meningkat dengan total keuntungan penjualan pertahun kedua adalah Rp. 19.187.280. Setelah tahun ke3 hingga sekarang, usaha ini semakin laris dengan total keuntungan penjualan adalah sebesar Rp. 31.798.800.

\section{KESIMPULAN}

Dari hasil penelitian, maka penulis menyimpulkan untuk memproduksi satu buah pastel, dibutuhkan biaya produksi sebesar Rp. $1.145 /$ bulan. Untuk memperoleh keuntungan, maka setiap bulannya home industry ini harus memproduksi sebanyak 1.552/bulan dan setelah melakukan penelitian, maka dapat dinyatakan home industry ini adalah salah satu jenis home industry yang menghasilkan banyak keuntungan, terbukti dari jumlah keuntungan di tahun terakhirnya beroleh Rp. 31.798.800.

\section{DAFTAR PUSTAKA}

Anita, U. (2014). Analisis Perhitungan Harga Pokok Produksi Sebagai Dasar Penetapan Harga Jual Produk Furniture (Studi kasus pada PT. Hanin Designs Indonesia Indonesian Legal Wood). Jurnal Ekonomi Akuntansi, 1-10.

Giatman, M. (2006). Ekonomi Teknik. Jakarta: Raja Grafindo Persada.

Maghfirah, M., \& Syam BZ, F. (2016). Analisis Perhitungan Harga Pokok Produksi dengan Penerapan Metode Full Costing pada UMKM Kota Banda Aceh. Jurnal Ilmiah Mahasiswa Ekonomi Akuntansi, 1(2), 59-70.

Maruta, H. (2018). Analisis Break Even Point (Bep) Sebagai Dasar Perencanaan Laba 
Bagi Manajemen. Sekolah Tinggi Ilmu Ekonomi (STIE) Syariah Bengkalis, 9-28.

Mulyadi. (2013). Akuntansi Biaya. (5th ed.). Yogyakarta: STIM.

Noodle, C., Tirta, P., Wening, W., Kartika, N., \& Mayasti, I. (2014). Analisa Kelayakan Finansial Pengembangan Usaha Produksi Komoditas Lokal: Mie Berbasis Jagung. Agritech: Jurnal Fakultas Teknologi Pertanian UGM, 34(2), 194-202. https://doi.org/10.22146/agritech.9510

Pelealu, A., Manoppo, W., \& Mangindaan, J. (2018). Analisis Perhitungan Harga Pokok Produksi Dengan Menggunakan Metode Full Costing Sebagai Dasar Perhitungan Harga Jual (Studi Kasus Pada Kertinaâs Home Industry). Jurnal Administrasi Bisnis, 6(002), 269396. https://doi.org/10.35797/jab.6.002.2018. 19850.
Rita, Lusi Maretti dan Sutrisna, E. (2016). JOM FISIP Vol. 3 No. 2 - Oktober 2016 Page 1. Jurnal Ilmu Komunikasi, 3(2), 1-15.

Setiyani, A. E. (2015). Perhitungan Harga Pokok Produksi Dan Harga Menggunakan Metode Full Costing Pada Home Industry Vania Bakery Di Semarang, 1-15.

Thoriq, A., Sampurno, R. M., \& Nurjanah, S. (2017). Evaluasi Ekonomi Teknik Produksi Keripik Kentang Secara Manual (Studi Kasus: Taman Teknologi Pertanian, Cikajang, Kabupaten Garut, Provinsi Jawa Barat). Jurnal Teknotan, 11(2), 43. https://doi.org/10.24198/jt.vol11n2.5 